\title{
Short term outcome, complications and average direct cost in managing extremely low birth weight infants in a tertiary care centre in Sri Lanka
}

\author{
U B Nelumdeniya ${ }^{1}$, P S De Silva ${ }^{2}$, S Nanayakkara ${ }^{3}$, S Sridharan ${ }^{2}$, K Srirathnakumar ${ }^{2}$, R C \\ Abeysirigunawardena ${ }^{2}$, S S Marasinghe ${ }^{2}$
}

Sri Lanka Journal of Child Health, 2012; 41(4): 186-191

\begin{abstract}
Introduction: Data on cost, short term complications and outcome of Sri Lankan extremely low birth weight (ELBW) babies is largely unavailable.

Objective: To determine the cost, selected short term complications (surfactant treated and untreated) and short term outcome of ELBW infants in a tertiary care unit in Sri Lanka.
\end{abstract}

Design, setting and method: A descriptive longitudinal study was carried out at Castle Street Hospital for Women over a 6 month period on all ELBW infants, excluding babies who were born after less than 23 completed weeks of gestation and babies who were transferred from the unit.

Results: During the study period there were 39 ELBW babies. Ranges of birth weights and maturity were from $540 \mathrm{~g}$ to $980 \mathrm{~g}$ (mean $853 \mathrm{~g}$ ) and from 25 weeks to $34+3$ days respectively. Fifty one percent were small for gestational age. Survival rate was $76.9 \%$ at discharge. Hospital stay, intensive care unit stay, duration of mechanical ventilation and supplemental oxygen were $60.6,13,3.5$ and 9.0 days per survivor respectively. Direct cost per survivor was SLR 82,207. Incidences of complications were $19.4 \%$ intraventricular haemorrhage, $8.3 \%$ necrotising enterocolitis, $22.2 \%$ pulmonary air leak, $11.1 \%$ pulmonary haemorrhage and $2.7 \%$ patent ductus arteriosus. Average weight gain on discharge was $5.2 \mathrm{~g} / \mathrm{kg} /$ day.

Conclusions: Overall survival rate was $77 \%$. IVH was significantly less in surfactant treated babies.

(Key words: Short term outcome; complications; extremely low birth weight infants)

${ }^{1}$ Acting Paediatrician, District General Hospital, Nuwara Eliya, ${ }^{2}$ Medical officer, ${ }^{3}$ Consultant Paediatrician, Neonatology Unit, Castle Street Hospital for Women, Colombo

(Received on 6 January 2012: Accepted after revision on 13 March 2012)

\section{Introduction}

Extremely low birth weight (ELBW) infants are those that weigh less than $1000 \mathrm{~g}$. Very low birth weight (VLBW) infants (less than 1500g) account for over $50 \%$ of neonatal deaths and $50 \%$ of handicapped infants; their survival is directly related to birth weight with approximately $20 \%$ of those between 500 and $600 \mathrm{~g}$ and over $90 \%$ of those between 1200 and $1500 \mathrm{~g}$ surviving in the United States ${ }^{1}$. Although the rate of low birth weight is available, we do not have a national figure for VLBW or ELBW. Castle Street Hospital for Women (CSHW) in Colombo caters for more than 18,000 births annually and in 2008, 3,344 babies were admitted to the neonatal unit of the hospital out of which $326(9.74 \%)$ babies were VLBW. In this hospital VLBW infants accounted for $47 \%$ of neonatal deaths ${ }^{2,3}$.

The care of ELBW neonates may impose an enormous burden on professional resources and finances of caregivers. The cost varies greatly between developed countries and developing countries and between different centres within a country or a region as it largely depends on the cost of sophisticated and advanced neonatal care and the cost of the health care system in general $^{4-8}$. Consequently, it is difficult to compare the cost among different centres. In a few studies costs were calculated by dividing the total number of hospital days or ventilator days before death or discharge home by the number of survivors in order to calculate the resource use and costs incurred per survivor ${ }^{7,9}$. This type of data on Sri Lankan babies is largely unavailable. However, it is essential to have this information to guide forward planning, therapeutic intervention, budgeting and staffing with the aim of improving outcome.

Surfactant replacement therapy for hyaline membrane disease (HMD) in premature infants has been shown to be safe and efficacious in many studies including a study done in Sri Lanka ${ }^{10}$. However, surfactant therapy is extremely expensive and we may not be able to afford it as prophylaxis for HMD in the government sector. 


\section{Objectives}

- To determine the outcome of ELBW babies born in CSHW during the study period

- $\quad$ To determine the incidence of selected short term complications

- To determine the average direct cost of managing such babies and

- To compare the incidence of selected short term complications among ELBW babies who receive surfactant and those who do not in the sample population

\section{Method}

A descriptive longitudinal clinical study was carried out at CSHW, Colombo during the six month period from $1^{\text {st }}$ December 2008 to $31^{\text {st }}$ May, 2009. The study was approved by the Ethical Review Committees of CSHW and Sri Lanka College of Paediatricians.

All live births with birth weights less than $1000 \mathrm{~g}$ born in CSHW during the study period were recruited after obtaining informed written consent. Infants with birth weights less than $500 \mathrm{~g}$, gestational age at birth less than 23 completed weeks, and infants who were transferred out for reasons other than surgical management of necrotising enterocolitis (NEC) or patent ductus arteriosus (PDA), were excluded from the study.

The data was collected by the investigators using a pretested standard questionnaire. Clinical notes from the babies and mothers were used to collect the relevant data. The birth weight was plotted on Fenton $^{11}$ growth charts to determine whether the baby was appropriate for gestational age (AGA), small for gestational age (SGA) or large for gestational age (LGA). All the survivors of the test population were examined by a consultant ophthalmologist for retinopathy of prematurity (ROP). These children were followed up until discharge from the ophthalmology clinic and findings of this referral were entered into the questionnaire. In the neonatology unit at CSHW a cranial ultrasound scan (USS) is done in all ELBW infants at the age of 7-14 days routinely or whenever intraventricular haemorrhage (IVH) is suspected. It is performed by the consultant radiologist on duty. Repeat USS is done on discharge or at 36-40 weeks postmenstrual age. In this study we collected data related to $\mathrm{IVH}$, germinal matrix haemorrhage $(\mathrm{GMH})$, periventricular leukomalacia (PVL) and ventriculomegaly (mild 0.5$1 \mathrm{~cm}$, moderate $1.0-1.5 \mathrm{~cm}$, severe $>1.5 \mathrm{~cm})$. The diagnosis of NEC was made if the baby had modified Bell's stage 2 or $3^{12}$.

The survival rate (percentage of babies who were live at discharge or by 40 week corrected gestational age), incidence and severity (stages 1-5) of ROP, incidence and severity of IVH, feeding method on discharge, weight gain/loss on discharge and supplemental oxygen on discharge were considered as short-term outcomes of infants.

In this study we used "average direct cost" which could be used easily to compare the costs taking into account the cost incurred on drugs as well. Average direct cost was calculated by considering the duration (cost) of hospital stay per survivor (total hospital days divided by number of survivors), neonatal intensive care unit (NICU) care cost (in days per survivor), costs of continuous positive airway pressure (CPAP)/intermittent positive pressure ventilation (IPPV)/oxygen therapy (in days per survivor), cost of surfactant and cost of intravenous (IV) antibiotics. Direct fixed cost (staff salary), indirect fixed cost (salaries of administrators, paramedics etc.), indirect variable cost (cost of water, telephone, electricity, diet of parents) and capital cost (cost of land, building, instruments and equipment) were not calculated.

The incidence of IVH, NEC, pulmonary air leak (PAL), pulmonary haemorrhage and clinical PDA were the selected short term complications looked for in this study.

\section{Results}

During the study period 39 ELBW babies (17 boys, 22 girls) were born in CSHW. Birth weights were between $540 \mathrm{~g}$ to $980 \mathrm{~g}$ (mean $853 \mathrm{~g}$ ) and the maturity was from 25 weeks to 34 weeks and 3days. Majority $(55.5 \%)$ were between 27 and 30 weeks of gestation and $700 \mathrm{~g}$ to $900 \mathrm{~g}(44.4 \%)$ weight at birth. $48.7 \%$ of birth weights were appropriate for gestational age (AGA) while 51.3\% were small for gestational age (SGA). None were large for gestational age (LGA). Distribution of the sample according to the birth weight, maturity and percentage of AGA babies is shown in table 1 . 
Table 1: Sample distribution

\begin{tabular}{|l|c|c|c|}
\hline \multicolumn{1}{|c|}{ Characteristic } & Number & Percentage & \% AGA \\
\hline Birth weight & 10 & 25.6 & 40.0 \\
$500-700 \mathrm{~g}$ & 16 & 41.0 & 56,2 \\
$701-900 \mathrm{~g}$ & 13 & 33.3 & 46.1 \\
$901-1000 \mathrm{~g}$ & & & \\
\hline Maturity & 13 & 33.3 & 76.9 \\
25 to $26+6$ weeks & 20 & 51.3 & 45.0 \\
27 to $29+6$ weeks & 02 & 05.1 & 0.0 \\
30 to $31+6$ weeks & 04 & 10.2 & 0.0 \\
\hline >32 weeks & 39 & 100 & 48.7 \\
\hline \multicolumn{1}{|c|}{ Total } & & & \\
\hline
\end{tabular}

Out of the babies recruited to the study, 3 died within 6 hours of age, 2 within 24 hours and the rest (4) within one week giving an overall survival rate of 76.9\%. Girls (81.8) did better than boys (70.6). With a few exceptions, survival rate increased with increase in the birth weight and the gestational age. (Table 2)

Table 2: Survival rates for birth weight and maturity bands of each gender

\begin{tabular}{|c|c|c|c|c|c|c|c|}
\hline Characteristic & \multicolumn{3}{|c|}{ Boys } & \multicolumn{3}{|c|}{ Girls } & Both \\
\hline & Total & Survived & \%Survival & Total & Survived & $\%$ Survival & Survival \\
\hline $\begin{array}{l}\text { Birth weight } \\
500-700 \mathrm{~g}\end{array}$ & 5 & 2 & 40.0 & 5 & 3 & 60.0 & 50 \\
\hline $701-900 \mathrm{~g}$ & 7 & 6 & 85.7 & 9 & 8 & 88.9 & 87.5 \\
\hline $901-1000 \mathrm{~g}$ & 5 & 4 & 80.0 & 8 & 7 & 87.5 & 84.6 \\
\hline Maturity & & & & & & & \\
\hline 25 to $26+6$ weeks & 7 & 4 & 57.1 & 6 & 4 & 66.7 & 61.5 \\
\hline 27 to $29+6$ weeks & 7 & 5 & 71.4 & 13 & 12 & 92.3 & 85.0 \\
\hline 30 to $31+6$ weeks & 1 & 1 & 100.0 & 1 & 1 & 100.0 & 100.0 \\
\hline$>32$ weeks & 2 & 2 & 100.0 & 2 & 1 & 50.0 & 75.0 \\
\hline Total & 17 & 12 & 70.6 & 22 & 18 & 81.8 & 76.9 \\
\hline
\end{tabular}

Hospital stay, intensive care unit (ICU) stay and nonICU stay were calculated by dividing total number of hours for each category (including those spent by non-survivors) by number of survivors. (Table 3)
Median maturity at discharge home was 35 weeks and 1 day. Corrected gestational age at discharge was between 33 weeks and 5 days to 50 weeks and 5 days.

Table 3: Cost of hospital stays (Average direct cost)

\begin{tabular}{|l|c|c|}
\hline \multicolumn{1}{|c|}{ Category } & Range (until discharge) & Cost \\
\hline Hospital stay & $17-114$ days & 60.6 days/survivor \\
\hline ICU stay & $0-46$ days & 13 days/survivor \\
\hline Non-ICU stay & $6-98$ days & 47.6 days/survivor \\
\hline Mechanical ventilation & $0-141$ hours & 3.5 days/survivor \\
\hline CPAP & $0-64$ hours & 2.2 days/survivor \\
\hline Nasal prongs oxygen & $24-310$ hours & 9 days/survivor \\
\hline Antibiotic days & $5-31$ days & 16 days/survivor \\
\hline Surfactant doses & $0-1$ doses & 0.33 doses/survivor \\
\hline Dopamine, dobutamine or both & $0-9$ days & 0.18 days/survivor \\
\hline
\end{tabular}


Table 4: Average direct cost in Sri Lankan Rupees (SLR)

\begin{tabular}{|lr|}
\hline \multicolumn{1}{|c|}{ Item } & Cost in SLR per survivor \\
\hline Mechanical ventilation & 12,272 \\
\hline CPAP & 6,554 \\
\hline Nasal prongs Oxygen/Face mask oxygen & 2,900 \\
\hline Incubator care & 6,843 \\
\hline Phototherapy & 228 \\
\hline Antibiotics (each vial was assumed to be shared by 3 patients on average) & 12,800 \\
\hline Surfactant, IVIG, Blood products, IV fluids & 30,590 \\
\hline IV sets, cannula, syringes, NG tubes, suction catheters & 2,260 \\
\hline Investigations including blood gas, excluding ultrasound scans & 6,160 \\
\hline Linen, cloths, swabs & 1,600 \\
\hline Total & 82,207 \\
\hline
\end{tabular}

In calculating direct cost, cost for ROP screening, laser therapy, costs of transportation were not included. Cost of enteral nutrition was not included as the data were not completed. None received TPN.
The average direct cost in Sri Lankan rupees (SLR) is shown in table 4. The incidence of selected complications is shown in table 5 .

Table 5: Incidence of selected complications

\begin{tabular}{|l|c|c|c|}
\hline \multicolumn{1}{|c|}{ Complication } & $\begin{array}{c}\text { Overall incidence } \\
\mathbf{( \% )} \mathbf{n}=\mathbf{3 6}\end{array}$ & $\begin{array}{c}\text { Incidence among surfactant } \\
\text { treated babies n=10 }\end{array}$ & $\begin{array}{c}\text { Incidence among untreated } \\
\text { (surfactant) babies n=26 }\end{array}$ \\
\hline IVH & $7(19.4)$ & $1(10 \%)$ & $6(23 \%)$ \\
\hline NEC & $3(8.3)$ & $1(10 \%)$ & $2(7.7 \%)$ \\
\hline PAL & $8(22.2)$ & $4(40 \%)$ & $4(15.3 \%)$ \\
\hline Pulmonary haemorrhage & $4(11,1)$ & $2(20 \%)$ & $2(7.7 \%)$ \\
\hline Clinical PDA & $1(2.7)$ & $0(0 \%)$ & $1(3.8 \%)$ \\
\hline
\end{tabular}

The incidence of selected complications was restricted to the 36 ELBW babies who survived for more than 6 hours after birth. One of the 7 babies with IVH had bilateral grade 4 IVH from which he succumbed.

Eye examination, done in the 36 ELBW babies who survived for more than 6 hours after birth, revealed the presence of ROP in 25 (83.3\%) babies on first eye examination. Incidence of stages 1, 2, and 3 ROP was $60 \%, 16.7 \%$ and $6.7 \%$ respectively. Only $5(16.7 \%)$ had completely normal retina on first ophthalmologic examination. None of the babies developed stages 4 or 5 ROP.

Average weight gain per survivor at discharge was $5.2 \mathrm{~g} / \mathrm{kg} /$ day. None of the babies were oxygen dependent or tube fed at discharge.

\section{Discussion}

Itabashi et al, in a study of 3,065 ELBW infants born in 2005 in Japan, showed that neonatal mortality rate and the mortality rate during NICU stay among ELBW infants were $13 \%$ and $17 \%$, respectively ${ }^{13}$. As all the deaths in our study occurred within first 7 days of life and during ICU stay, neonatal mortality rate and the mortality rate during NICU stay can be calculated as $23 \%$ and $25.7 \%$ respectively ( 4 babies did not get admitted to NICU). In another study done in South Africa, overall survival rate of VLBW was $70.5 \%$ and survival rate of ELBW infants was $34.9 \%{ }^{14}$. In our study the overall survival rate of ELBW infants was $77 \%$.

The cost of managing ELBW infants varies between developed and developing countries and different regions within a country ${ }^{4,6,15,16}$. Furthermore, it is 
difficult to compare the costs between different centres due to vast differences in labour costs and the cost of medications. Thus it is reasonable to calculate costs in terms of hospital stay, ICU stay duration of mechanical ventilation etc. Analyzing data from 5,364 infants with birth weight 501-1000g born in USA, Walsh et al found that median duration of ventilation for survivors was 23 days ${ }^{17}$. In the South African study ${ }^{14}$, mean duration of mechanical ventilation was 8.08 days and the mean duration of supplemental oxygen was 8.2 days in VLBW babies. In our study mean duration of mechanical ventilation and supplemental oxygen was 3.5 days and 8.9 days respectively.

Approximately $30 \%$ of VLBW premature infants have IVH and $11.4 \%$ of ELBW infants have grades 3 or 4 (severe) $\mathrm{IVH}^{18}$. In our study $19.4 \%$ ELBW infants had IVH and $2.7 \%$ had severe IVH. However this may be an under estimate as not all the babies who died early had cranial ultrasound scans. Only one out of the 7 babies who developed IVH had received surfactant replacement therapy compared to 6 who had not received surfactant $(\mathrm{P}<0.001)$. Otherwise the complications were similar in those receiving and not receiving surfactant therapy.

UK ROP screening guidelines recommend that first ROP screening should be undertaken at 30 to 31 weeks postmenstrual age for the babies born before 27 weeks and between 4 to 5 weeks postnatal age for babies born between 27 and 32 weeks. For babies $>32$ weeks gestational age but with birth weight $<1501 \mathrm{~g}$ first ROP screen should be undertaken between 4 to 5 weeks ${ }^{19}$. In general, more than $50 \%$ of premature infants weighing less than $1250 \mathrm{~g}$ at birth show evidence of ROP, and about $10 \%$ of the infants develop stage $3 \mathrm{ROP}^{19}$. In our cohort $25(83.3 \%)$ showed evidence of ROP and $2(6.7 \%)$ had stage 3 ROP.

\section{Conclusions}

- ELBW babies in this study had an overall survival rate of $77 \%$.

- Mean duration of mechanical ventilation was 3.5 days and the mean duration of supplemental oxygen was 8.9 days.

- IVH, NEC, PAL, pulmonary haemorrhage and clinical PDA occurred in $19.4 \%, 8.3 \%, 22.2 \%$, $11,1 \%$ and $2.7 \%$ respectively.

- IVH was significantly less in babies treated with surfactant.

\section{Limitation of the study}

Small sample size is the biggest limitation of this study.

\section{References}

1. Lawn JE, Cousens S, Zupan J, et al,. 4 million neonatal deaths: When? Where? Why? Lancet 2005; 365:891-900. http://dx.doi.org/10.1016/S0140-6736(05)71048-5

2. Annual health Bulletin of Sri Lanka 2006

3. Annual Statistics Bulletin of Castle Street Hospital for Women Colombo. 2008. P 10-14

4. Tongo OO, Orimadegun SO, Akinyinka OO. The economic burden of preterm/ Very low birth weight care in Nigeria. Journal of Tropical Pediatrics 2009; 55(4):262-4.

http://dx.doi.org/10.1093/tropej/fmn107

5. Sharon K, Jays G, Michael K, Roy S. Clinical outcome and cost of the moderately preterm infant. Advances in Neonatal Care 2007; 7(2):80-7.

6. Schmitt SK, Sneed L, Phibbs CS. Cost of newborn care in California: A population based study. Pediatrics 2006; 117(1):154-60. http://dx.doi.org/10.1542/peds.2005-0484

7. Tyson JE, Younes N, Verter J, Wright LL. Viability, morbidity, and resource use among newborns 501- to $800 \mathrm{~g}$ birth weight. Journal of the American Medical Association 1996; 276:1645-51.

http://dx.doi.org/10.1001/jama.276.20.1645

8. Lorenz JM, Paneth N, Jetton JR, et al. Comparison of management strategies for extreme prematurity in New Jersey and the Netherlands: Outcome and research expenditure. Pediatrics 2001; 108:1269-74. http://dx.doi.org/10.1542/peds.108.6.1269

9. Tyson E, Parikh NA, Langer J, Green C, Higgins RD. Intensive care for extreme prematurity: Moving beyond gestational age. New England Journal of Medicine 2008; 358:1672-81. http://dx.doi.org/10.1056/NEJMoa073059 
10. Menike KAN, Weerasekara M. Outcome of surfactant therapy in a tertiary referral centre in Sri Lanka. Sri Lanka Journal of Child Health 2009; 38:25-7

http://dx.doi.org/10.4038/sljch.v38i1.571

11. Fenton TR. A new fetal-infant growth chart for preterm infants developed through a metaanalysis of published reference studies. $B M C$ Pediatrics 2003; 3: 13.

http://dx.doi.org/10.1186/1471-2431-3-13

12. Bell MJ, Ternberg JL, Feigin RD, Keating JP, Marshell R, Barton L, et al. Neonatal necrotizing enterocolitis: therapeutic decisions based upon clinical staging. Annals of Surgery 1978; 187:1-7. http://dx.doi.org/10.1097/00000658-197801000$\underline{00001}$

13. Itabashi K, Horiuuchi T, Kusuda S, Kabe K, Itani Y, Nakamura T, et al. Mortality rates for extremely low birth weight infants in Japan in 2005. Pediatrics 2009; 123(2):445-50. http://dx.doi.org/10.1542/peds.2008-0763

14. Ballot DE, Chirwa TF, Cooper PA. Determinants of survival in VLBW neonates in a public sector hospital in Johannesburg. BMC Pediatrics 2010; 10:30.

http://dx.doi.org/10.1186/1471-2431-10-30
15. Gilbert W, Nesbitt TS, Danielsen B. The cost of prematurity: Quantification by gestational age and birth weight. Journal of Obstetrics \& Gynecology 2003; 102(3):488-92.

http://dx.doi.org/10.1016/S0029-7844(03)00617-3

16. Kirkby S, Greenspan JS, Kornhauser M, Schneiderman R. Clinical outcome and cost of the moderately preterm infants. Advances in Neonatal Care 2007; 7(2):80-7.

17. Walsh MC, Morris BH, Wrage LA, Vohr BR, Poole WK, Tyson JE, et al. Extremely low birth weight neonates with protracted ventilation: mortality and 18 month neurodevelopmental outcome. Journal of Pediatrics 2005; 146(6):798-804.

http://dx.doi.org/10.1016/j.jpeds.2005.01.047

18. Chapman IA, Stoll BJ, editors. Nelson Textbook of Pediatrics. $18^{\text {th }}$ ed. New Delhi: Elsevier; 2008.p.715-717

19. Royal College of Ophthalmologists and Royal College of Paediatrics and Child health. Guideline for the screening and treatment of retinopathy of prematurity. (monograph on the internet). Available from: www.rcophth.ac.uk/core/core picker/download.a $\underline{\mathrm{sp} ? \mathrm{id}=180}$ 